\title{
The Protection and
}

Preservation of Soils

Fertility in Banat

\section{The Quality Form of Agricultural Soils}

Ianoş, G.*

Abstract In the context of preserving and increasing the land fertilities of Banat, it has been made a detailed analysis of the risk factors of agricultural production, generating factors of limitations because of relief, clime, drainage conditions, of the chemical and physical characteristics as well as because the degrading interventions and the polluting ones made by men, in parallel being proposed solutions and have been dimensioned a number of ameliorative interventions at different levels of complexity.

The evaluation of the capacity of the agricultural terrain's of supporting the production for a certain type of usage as well as the different possibilities of support of the different agricultural terrain's for different traditional cultures has been realised by a detailed analysis of, the elements of the environment and soil, finalised by actions of quantification and parameterisation of the mentioned factors and their processing on the basses of typical work methodology.

The researched area in of 1,198,264 ha, representing the total agricultural surface of the Romanian Banat. The global (medium) possibility of the terrain's with agricultural destination (divided in 10 classes) is placed around the sixth class for the arable utilities, orchards and vineyard, of the fifth class for hay utility and of the fourth class for pasture utility. The grouping concerning the sustainability of the arable terrain's (also divided on 10 classes) is specifying an enriched favorability for the culture of what and corn (class. IV), followed by the culture of rice, sun flower, soya etc). The possibility of the Banat terrain's of supporting enriched agricultural productions in dwindling from the est. to the west and from north to south.

Key words soils, degradation, melioration, fertility, Banat, Romania

Gheorghe Ianoş, West University of Timişoara, Dept. of Geography, B-dul. V.Pârvan 4, 300.223 Timişoara, Romania; ianos@cbg.uvt.ro
W th all its typical organisation and of the multiple interval and external connections, soil as a mean of vegetal production can be considered a result of agricultural activities.

The last decades of agricultural activity have marked a true quantitative explosion of products not only due to genetically engineering but also due to an intensive mechanisation and chemicalisation. On the other hand the rush of overproduction in agriculture means the deterioration of some physical properties and the exhausting of some nutritive elements in soil and finally the degradation of the environment.

Banat agriculture generally and that of Timiş District especially presents some particularities that are not similar with those in other districts of the country or with those of countries with a developed agriculture. About those particularities we shall refer especially in the context of some limitative or degradational phenomena.

The researches performed on a certain area of 1,198,264 ha, representing the cultivated land of the Banat province, were made in following stages: a) studies of the ground for the identification and cartography of the soil conditions and for the investigation of natural conditions; b) analytical laboratory determinations on representative soil samples; c) making a legend of the soil and ground units which included $292 \mathrm{di}$ visions, each division being characterised by 72 synthetic indicators of environment and soil; d) by plotting there were established the expansion areas for each ground and soil unit; e) the final stage consisted of computer processing of more than 20,000 coefficients, in accordance with a standardised methodology and some specific schedules.

Depending on the workability of each soil and ground unit for agricultural usage, there was elaborated a series of categories regarding the intensity of the limitative and restrictive factors, as follows: $\mathbf{1}=$ no limitations; $\mathbf{2}=$ reduced limitations; $\mathbf{3}=\bmod$ erate limitations; $\mathbf{4}=$ severe limitations; $\mathbf{5}=$ very severe limitation; 6 = extremely severe limitations (restrictions), as it follows: a) cultivated land degradation processes caused by climate conditions:

thermal conditions: 1.- 739,434 ha (61.7\%); 2. - 392,383 ha (32.7\%); 3. 22,880 ha (1.9\%); 4. - 42,567 ha (3.55\%); 5. $-2,000$ ha $(0.2 \%)$;

pluviometric conditions: 1. - 1,007,716 ha $(84.10 \%) ; 2$. - 95,583 ha $(7.98 \%)$; 3. $-81,198$ ha $(6.78 \%) ; 4$. $-13,767$ ha (1.15\%);

eolian condition: $3 .-2,100$ ha $(0,2 \%)$;

b) cultivated land degradation processes caused by relief factors, (fig.1):

lack of uniformity: 1. - 138, 71 ha (11.57\%); 2. - 448,673 ha (37.45\%); 3. - 252,023 ha (21.03\%); 4. - 181,513 ha (15.15\%); 5. - 177,384 ha (14.80\%); covering with rocks and/or boulders: 1. - 983,525 ha (82.08\%); 4. - 72,524 ha $(6.05 \%) ; 5 .-68,283$ ha $(5.70 \%) ; 6$. 73,932 ha $(6.17 \%)$;

- the proclivity: 1. - 683,298 ha (57.02\%); 2. - 150,646 (12.57\%); 3. - 144,857 ha $(12.1 \%) ; 4$. $-93,767$ ha $(7.83 \%) ; 5$. - 68,999 ha (5.76\%); 6. - 56,597 ha (4.72\%);

erosion danger: 1. - 755,653 ha (63.06\%); 2. - 54,538 ha $(4.55 \%) ; 3$. 169,259 ha $(14.13 \%) ; 4$. $-218,814$ ha (18.26\%);

sheet erosion: 1. - 1,039,253 ha (86.73\%); 2. - 17,870 ha $(1.48 \%) ; 3$. - 90,952 ha (7.59\%); 4. - 18,053 ha (1.51\%); 5. - 4,675 ha $(0.39 \%) ; 6$. 27,461 ha (2.29\%);

deep erosion: 1. - 764,500 ha (63.80); 2. - 123,355 ha (10.29\%); 3. - 196,681 ha (15.41\%); 4. - 113,728 ha (9.50\%); land slides: 2 - 130,166 (10.86\%);

c) limitation and restriction determined by drainage conditions:

excess of phreatic waterlogging (fig.1): 1. - 784,979 ha (56.50\%); 2. - 210,862 ha (17.60\%); 3. - 176,368 ha (14.72\%); 4. 23,535 ha (1.96\%); 5. - 2,520 ha (0.21);

excess of stagnic waterlogging: 1 . 751,236 ha (62.70\%); 2. - 167,569 ha (13.98\%); 3. - 120,789 ha $(10.08 \%)$; 4. - 158,353 ha $(13.22 \%) ; 5$. 317 ha (0.02\%);

excess of flood humidity: 1. - 1,156,824 ha (96.65\%); 5. - 41,440 ha (4.36\%);

exces of humidity due to the lateral infiltrations in soil on the versants:1. $1,059,973$ ha (88.46\%); 2. - 104,038 ha $(8.68 \%) ; 3 .-20,235$ ha $(1.69 \%) ; 4$. 11,498 ha (0.96\%); 5. - 2,520 ha (0.21\%);

d) limitations and restrictions determined by their chemical characteristics (fig. 2):

salinisation: $1 . \quad-1,121,082$ ha (93.56\%); 2 .- 64,835 ha (5.41\%); 4.9,852 ha $(0.82 \%) ; 5 .-2,495$ ha $(0.21 \%)$; alcalisation: $1 .-1,087,284$ ha $(90.73 \%)$ 2. - 66,934 ha (5.59 ha); 4. - 18,415 ha 


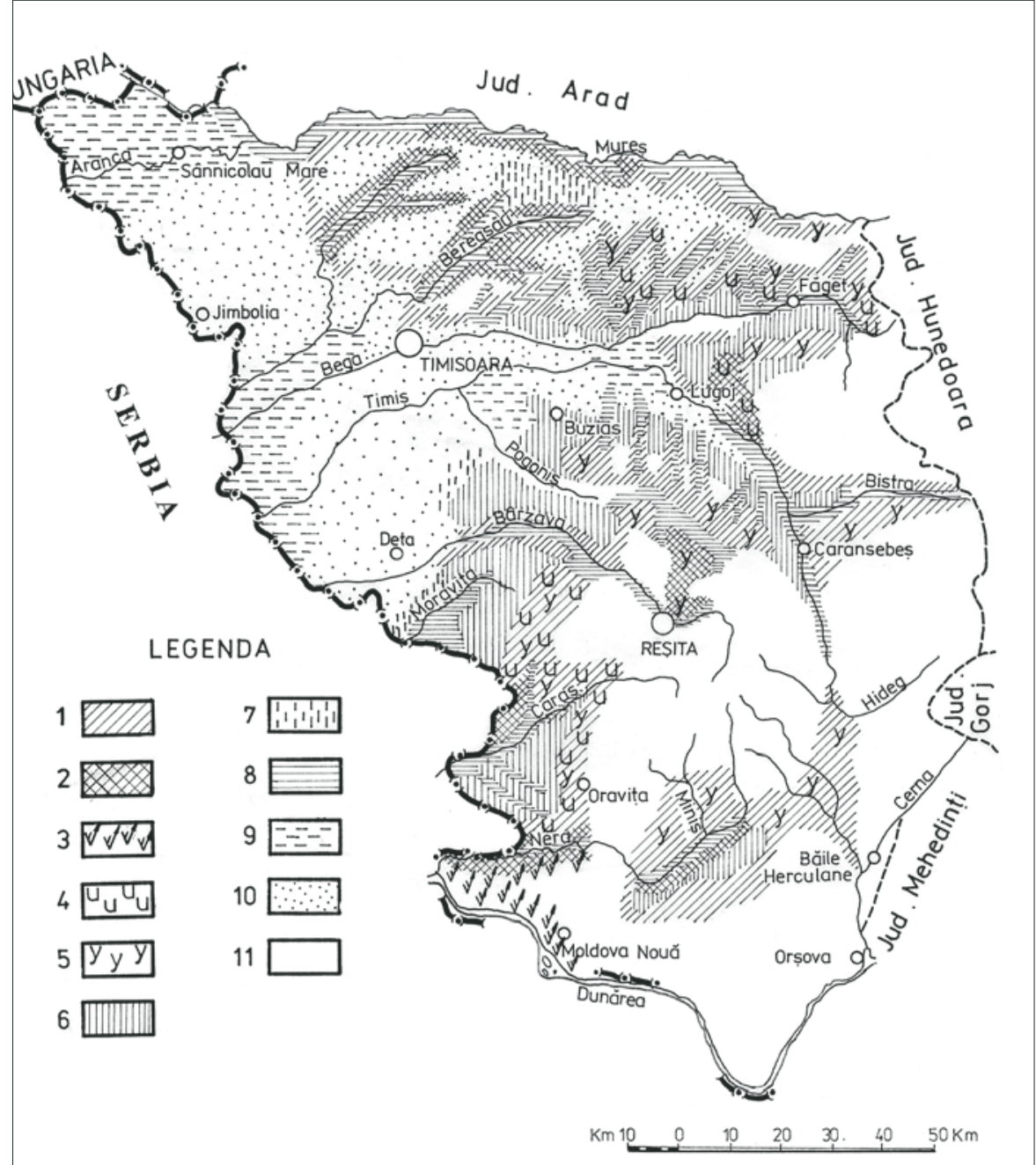

Figure 1. The agricultural lands in Banat affected by degradation owing to erosion, land slides and excess of humidity

LEGEND: Erosion by moderate-strong water; 2 . Erosion by very strong and excessive water; 3 . Wind (eollian) erosion; 4. Stabile of land slides; 5.Gully erosion; 6. Pluvial waterlogging (frecvently); 7. Pluvial water excess (periodical); 8. Phreatic humidity excess (frequently); 9. Phreatic humidity excess (periodical) associated with excess of pluvial humidity (periodical); 10. Unaffected land by degradation; 11 Forests and unmapped zones

(1.54 \%); 5. - 13,684 ha (1.14\%); 6. 11,947 ha $(1.0 \%)$;

depletion of bases: $1 .-498,883$ ha (41.63\%); 2 - 237,591 ha (19.83\%); 3 - 159,013 ha (13.27\%); 4 - 199,021 ha (16.61\%); 5 - 103,756 ha (8.66\%);

- humus storage: $1-462,169$ ha $(38.95 \%) ;$ $2-250,495$ ha (20.90\%); 3 - 239,140 ha (19.58\%); 4 - 198,799 ha (16.59\%); 5 47,661 ha $(3.98 \%)$;

content of $\mathrm{CaCO}_{3}: 2 .-143915$ ha (12.0\%);

deficiency of nutritive elements: available nitrogen - 287,799 ha (24.0\%); exchangeable phosphate - 290,174 ha (24.2\%); exchangeable potassium 231,011 ha (19.3\%);

e) limitations and restrictions determined by physicaly characteristics:

- coarse texture: - 320,275 ha (1.69\%); fine texture: 3. - 108,632 ha (9.07\%); 4 . - 409,417 ha (34.17\%); 1. - 659,940 ha (55.01\%);

reducing edaphyc useful volume: 1 . $1,028,210$ ha (85.81\%); 2. - 60,503 ha (5.05\%); 3. - 2,919 ha (0.24\%); 4. - 1,035 ha $(0.09 \%) ; 5 .-76,508$ ha $(6.38 \%) ; 6$. 29,089 ha (2.43\%);

reduced portance: 1 . - 1,147,647 ha (95.75\%); 2. - 16,170 ha (1.35\%); 3. 34,447 ha (2.87\%); 4. - 317 ha $(0.03 \%)$;

Factors and polluting activities in the soils of Banat. The placing of pollution in Banat and its serious implications on the quality and quantity of agricultural production and finally on human health calls a thorough research on types of sources.

There have been regarded the sources of pollution: 1 . by escavation - 732 ha; 2. by soil covering with soil banks, sedimentation ponds, sterile deposits, trash deposits - 545 ha; 3 . with industrial wasters and anorganical residues -104.9 ha; 4 . with heavy metals (in detailed - Gh.Ianoş, M.Goian,1995); 5. with radioactive materials - 8 ha; 6 . with hydrocarbons - 203.6 ha; 7. with wasters and organic residues that came from alimentary and easy industry 7 ha; 8 . with animal residues - 228 ha.

Proposals for measures taking for the protection, preservation and remaking of the agricole soils fertility were made
Proposed measures for the protection, preserving and remake of the soil fertilities in Banat.

For the remaking of the soils' fertility of Banat the following interventions are necessary:

Funciary Management and improvement: river course regularisation $-72,611$ ha (6.06\%); deep drainage - 477,917 ha (39.88\%); surface drainage - 282,699 ha (23.59\%); surface drainage and deep drainage - 158,620 ha (10.77\%); management antierosional works - 128,994 ha (10.77\%); ravines and torrents reclamation $-84,252$ ha $(7.03 \%)$; slides stopped for reclamation - 130,116 ha (10.86\%).

Agro-pedoameliorative works: liming 500,360 ha $(41.76 \%)$; gypsum melioration: $1^{\text {st }}$ urgency $-11,947$ ha $(1.0 \%) ; 2^{\text {nd }}$ urgency $-13,684$ ha $(1.14 \%) ; 3^{\text {rd }}$ urgency $-15,486$ ha (1.29\%); salt washing $-12,347$ ha $(1.03 \%)$; deep loosening: $1^{\text {st }}$ urgency $-81,115$ ha $(6.76 \%) ; 2^{\text {nd }}$ urgency $-119,819$ ha $(10.1 \%)$; $3^{\text {rd }}$ urgency $-64,638$ ha $(5.39 \%)$; meliorative fertilisation $-47,666$ ha (3.98\%); gash trench and wriggles unpermanent unsystematic reclamation of excess water flow - 65,518 ha (5.47\%), same, systematic 515,013 ha (43.98\%); mole drainage works - 177,387 ha (14.8\%); land bedding - 79,714 ha $(6.05 \%)$; obliged sense of works at agricultural machines in the water flow direction $-683,298$ ha $(57.03 \%)$; work system on the general direction of contour line 150,646 ha (12.5\%); antierosional systems of lands cultivation $-144,957$ ha $(12.1 \%)$; antierosional system of herb bands 93,767 ha $(7.83 \%)$; protection assolaments $-68,999$ ha (5.76\%); perenne herbs cultivation - 56,597 ha (4.72\%).

\section{Modifications of the physical and chemical properties of the soils under the impact of the agro-pedo-hydro- meliorative workings.}

The drainage workings done during the last decades have been extending on 466,000 hectares including 72 ameliorative systems and 10 exploitation systems. Therefore we can say that they gave huge lands to agriculture knowing that Banat was covered by huge muddy areas.

The relatively short time that has passed ever since the ceasing of the works concerning the control of humidity excess in certain zones of Banat did not facilitate the sesisation of some visible modifications in the morphology of the soils or other analytically determined ones. To all these we have to add the lack of a determined scientific control referring to the evolution of the soils in these areas both past and present. 
Yet some morphological characteristics indicate the more and more frequent gleisation phenomena as relict phenomenon that got stronger also as a result of the humidity deficit perceived during the last decades. This humidity deficit had lead to the accentuation of the stepisation in the low plain with the whole chain of negative effects. The poisonous salts have intensified their rise on the soil profile and the natrium ion is slowly climbing the superior horizons. Without the danger of reaching the epipedones. The exudative hydric regimes placed in the low plain soils of Banat during the last decade can create great problems in the future. The functionality of the great drainage systems foreseen with a great deal of pumping drainage stations in natural deversors is damaged by the lack of an adequate legislation and by the financier and energetically penury. The drainage channels, that were periodically requesting drainage's are more and more overfilled by used waters diversations from the zootechnical complex. If to all these organising shortcomings one would add a longer period of pluvial excess of humidity, the phreatic level will rise, at least on certain sectors, fact that will surely lead to the natrium penetration in the colloid complex of the horizons that support and feed the plants.

Of course, the most affected zones will be those were there where signalised the highest accumulations of salts i.e. the low loess plains where there are even now going on changes of ion positions.

The accentuated geometrisation of the drainage system stopped the total solving of the excess of stagnant humidity. Together with the designing imperfections the natural compaction and the artificial settling as a result of the anthropical intervention, lead to the maintenance of the danger of stagnant excess on some more 282,699 ha.

The supplementary addition of water by irrigation on the soils of the low plain is imposed by the uneven repartition of the precipitation's especially in the vegetation period and recently by accentuated fall of the phreatic level as a result of the depth drainage works.

In Banat such out fittings of land emprovals are extended on a surface of 17,216 ha in two systems: Arad-Fântânele (in the high plain) and Şag-Topolovăț (in the low plain). In both cases there were signalised favourable evolutions of the balance SH:SB and of the concentration of the natrium ion and unfavourable evolutions in the case of the physical and hydrophysical indices (DA, $\mathrm{PT}, \mathrm{Pa}$, structure).

A definitely special problem but very serious with acute manifestations in the past and probably in the future to is the erosion. Recently the surface erosion is affecting in different degrees of intensity about

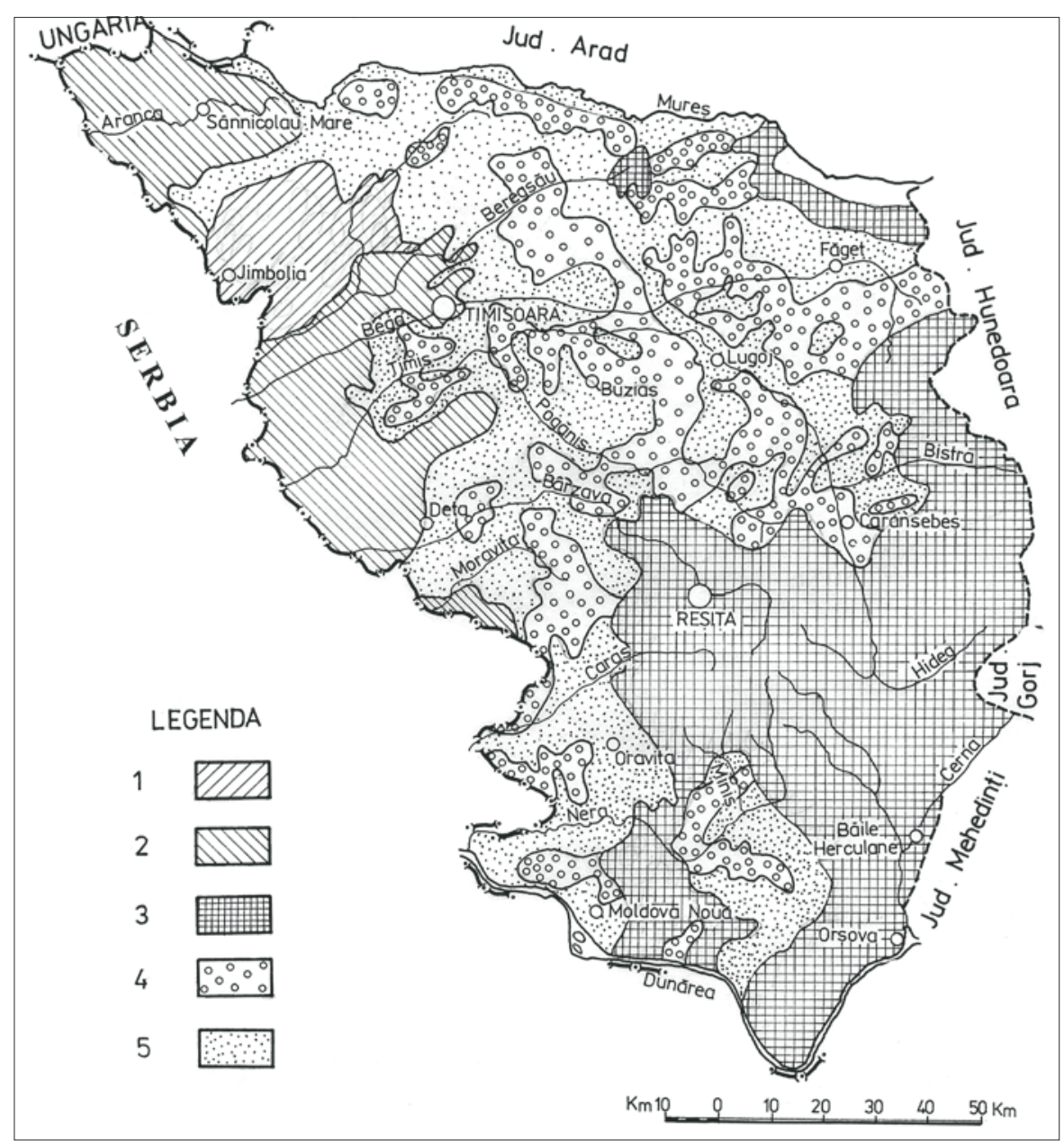

Figure 2. The agricultural lands affected by degrading through salting and acidification Legend: 1 . Moderate - strongly salted soils, in association with $90 \%$ zonal soils unaffected by salting. 2. Moderate - strongly salted soils, in association with $60 \%$ zonal soils unaffected by salting; 3 . Forests and unmapped zones; 4 . Moderate - strongly acid soils; 5 . Unaffected soils by salting or acidification

$13,27 \%$ of the surface of the agricultural soils placed on differently inclined slopes. The little extended antierosional systems of 82,313 ha (of which half in Caraş Severin District) did not solve only in a few cases the phenomenon and only partially.

The making of the usual agricultural works at improper states of humidity have lead to the extension of compactness phenomenon. In Banat there are 39,451 ha $(3.3 \%)$ of soils affected by severe limitations (strongly compacted), 201,845 ha (26.84\%) of land occupied by soils affected by limitate moderation's (medium compacted) and 285,955 ha (23.86\%) lands oc cupied by soils with reduced limitations (weakly compacted).

The same causes generate also structural degradations of the epipedons, causes to which there is also added the alarming dwindling of the humus percentage, fact that reduces the hydric and mechanic resistance of the structural aggregates.

Without considering that we finished at least a little part of this problem referring to the impact of the anthropical activity on the state of quality of the organisation of agricultural lands we cannot forget some preasures that were done on the environment by some operations of the territory. The looting that was done due to a high de- gree of geometrisation was placed over the multiple natural limits creating an ecological heterogeneity.

Subordinated to this ideas there have appeared tenth of hectares of protection curtains, tree clusters, bushes etc. This fact has determined the disparition of some typical microclimates, a perturbance of the ecological equilibrium and indirectly an intensification of pluviodenudation and erosion, the recrudescence of land slidings or intensification of deflation.

In the recent action peasant land giving one must follow the idea of protection and preservation of the soils by the correct orientation of the lots from the first phases of application of Law 18/1991. These actions are not singular, they even represent fundamental ideas in the organisation of the territory in the developed countries.

\section{The quality of the agricultural lands in Banat concerning their production capacity.}

Over the qualitative background of the soils there were placed the characteristics of the environment and there was made an evaluation of the state of quality by natu- 
Table 1. The Classes of pretability of the agricultural soils of Banat (according to the agricultural surface-1,198,264 hectares)

\begin{tabular}{|c|c|c|c|c|c|c|}
\hline \multirow{2}{*}{$\begin{array}{l}\text { The class of } \\
\text { pretability - points }\end{array}$} & \multirow{2}{*}{ UM } & \multicolumn{5}{|c|}{ Usage (ha / \%) } \\
\hline & & Arable & Pastures & Hays & Orchards & Vineyards \\
\hline \multirow{2}{*}{$\begin{array}{c}\mathrm{I} \\
91-100\end{array}$} & $\mathrm{Ha}$ & 105,362 & 24,073 & - & 86,398 & 18,708 \\
\hline & $\%$ & 8.80 & 2.01 & & 7.22 & 1.57 \\
\hline \multirow{2}{*}{$\begin{array}{c}\text { II } \\
81-90\end{array}$} & $\mathrm{Ha}$ & 114,798 & 345,825 & 72,143 & 68,987 & 155,136 \\
\hline & $\%$ & 9.59 & 28.87 & 6.03 & 5.76 & 12.95 \\
\hline \multirow{2}{*}{$\begin{array}{c}\text { III } \\
71-80\end{array}$} & $\mathrm{Ha}$ & 104,343 & 135,013 & 309,502 & 59,582 & 60,244 \\
\hline & $\%$ & 8.71 & 11.27 & 25.83 & 4.98 & 5.03 \\
\hline \multirow{2}{*}{$\begin{array}{l}\text { IV } \\
61-70\end{array}$} & $\mathrm{Ha}$ & 67,046 & 165,767 & 58,556 & 134,749 & 74,257 \\
\hline & $\%$ & 5.60 & 13.84 & 4.89 & 11.25 & 6.20 \\
\hline \multirow{2}{*}{$\begin{array}{c}\mathrm{V} \\
51-60\end{array}$} & $\mathrm{Ha}$ & 137,531 & 249,044 & 295,807 & 82,885 & 47,554 \\
\hline & $\%$ & 11.48 & 20.79 & 24.69 & 6.92 & 3.97 \\
\hline \multirow{2}{*}{$\begin{array}{c}\mathrm{VI} \\
41-50\end{array}$} & $\mathrm{Ha}$ & 139,101 & 108,082 & 125,720 & 117,104 & 94,585 \\
\hline & $\%$ & 11.61 & 9.02 & 10.50 & 9.78 & 7.90 \\
\hline \multirow{2}{*}{$\begin{array}{c}\text { VII } \\
31-40\end{array}$} & $\mathrm{Ha}$ & 161,304 & 53,858 & 164,936 & 173,355 & 166,403 \\
\hline & $\%$ & 13.40 & 4.50 & 13.77 & 14.40 & 13.89 \\
\hline \multirow{2}{*}{$\begin{array}{c}\text { VIII } \\
21-30\end{array}$} & $\mathrm{Ha}$ & 118,944 & 52,690 & 69,257 & 127,568 & 145,254 \\
\hline & $\%$ & 9.93 & 4.38 & 5.78 & 10.65 & 12.13 \\
\hline \multirow{2}{*}{$\begin{array}{c}\mathrm{IX} \\
11-20\end{array}$} & $\mathrm{Ha}$ & 93,004 & 64,233 & 90,079 & 145,242 & 133,771 \\
\hline & $\%$ & 7.77 & 5.37 & 7.52 & 12.13 & 11.17 \\
\hline \multirow{2}{*}{$\begin{array}{c}\mathrm{X} \\
1-10\end{array}$} & $\mathrm{Ha}$ & 156,831 & - & 12,264 & 202,394 & 302,357 \\
\hline & $\%$ & 13.09 & & 1.02 & 16.87 & 25.23 \\
\hline
\end{tabular}

ral bonitation, according to typical methodology of the domain (Teaci, 1980; ICPA, 1987). The totality of the factors studied (17 in our case), were quantified, codified, and processed with a typical software. Each area was given a qualification from 0 (improper) to 100 (optimal). For an efficient graphic representation, the exten sion period was divided into 10 or 5 subdivisions (classes of quality), from 10 to 10 points, i.e. from 20 to 20 points, where class I is optimal and class X (i.e. the $\mathrm{V}$ the in case of grouping the lands from 20 to 20 points) is improper (or of very weak quality for the agricultural production). The operation was done for 5 categories of usage of the agricultural soils (table 1) and for 5 plants that are raised preponderantly on the agricultural soils of Banat (table 2, fig. 3).

Such operations about the state of quality of the agricultural terrain's were done in different periods of time different methodologies, both for restrained areas as well as for the entire surface of Romania. A first general evaluation of the quality of soils in Romania was done Romania in 1975 at the scale 1:50,000. Later there were done studies at high scales $(1: 10,000)$ for the majority of the communal terrain's placed in areas with arable resources. For the regional units, these studies were done isolated (Ianos \& al., 1985, 1987)

Once the state of quality established of each land area (ecologically homogenous) and marking it on 100 points interval, there can be easily made a prognosis for the value of the value of the productions possibly to be obtained in different technological situations. tity of products for each bonitation point. In case that the government mechanisms are interfering by certain facilities, the re- covery of the invested capital can be done by reshaping the values attributed to each bonitation point and for each culture.

\section{Conclusions}

1. The majority of the agricultural lands from the Romanian Banat suffers of one or more restrictive or degrading factors because of the general characteristics of the environment or the anthropical influences in a special way. To these it could be added the degrading impacts under different forms and varied intensities which have put out partially about 1,500 ha of productive lands from the agricultural circuit.

2. For the remaking of the fertility of the degrading agricultural lands these have been proposed and dimensioned a number of funciary management measures and of agro-pedo-melioration works.

3. The naturalistic-economic bonitation of the agricultural soils of Banat was done by bonitation actions. The terrain's with agricultural destination (appreciated function of the scale of bonitation, medium ponderate), are in the $\mathrm{VI}^{\text {th }}$ class of pretability for arable, orchards, vineyards, in the $\mathrm{V}^{\text {th }}$ class for hays and the IV ${ }^{\text {th }}$ class for pastures. For arable usage, the most favourable cul-

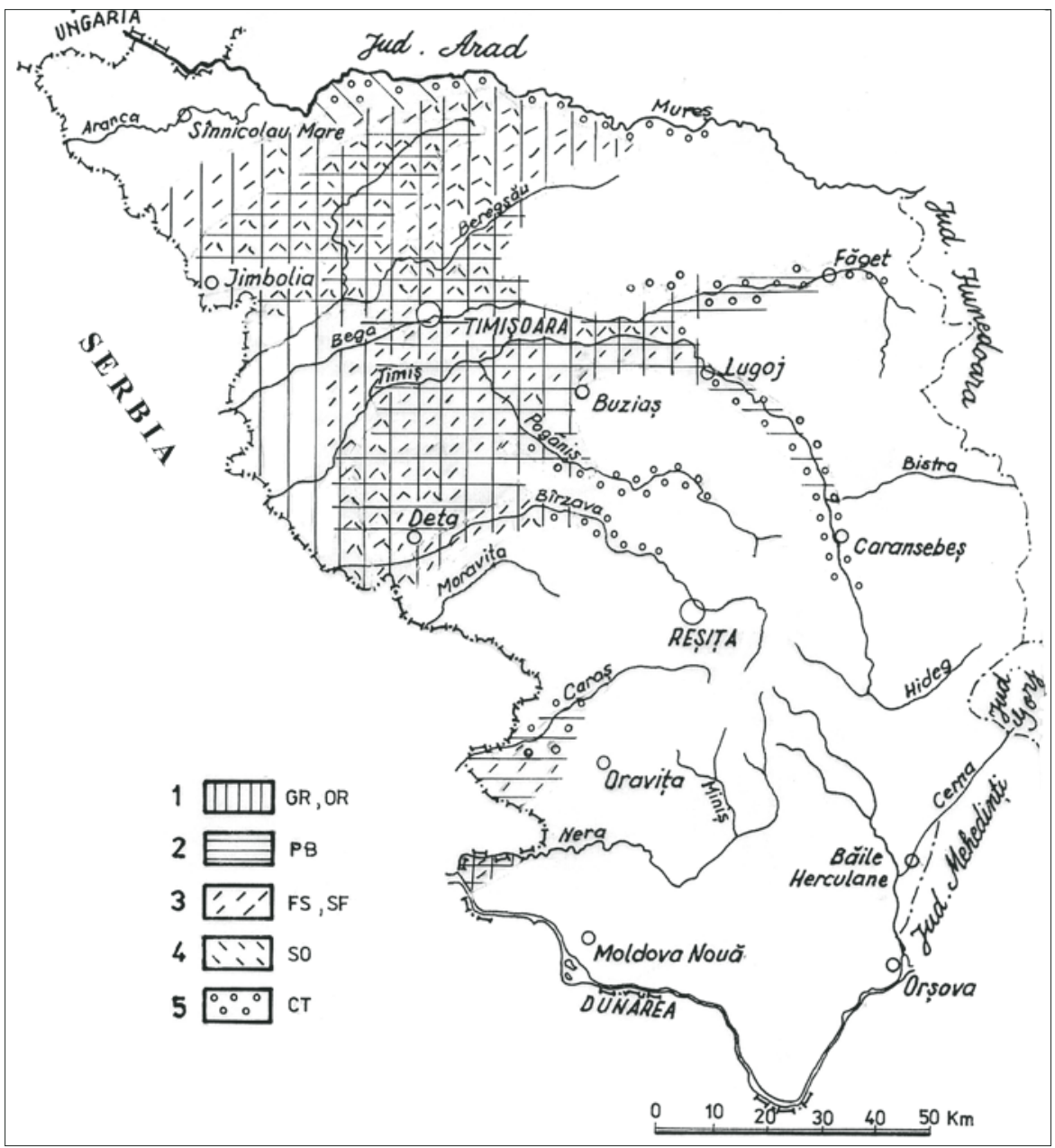

Figure 3. Agricultural areas in Banat, with high suitability for cereals and technical plants Legend: 1. wheat and barley; 2. maize; 3. sun-flower and sugar-beet; 4. soya beans; 5 . potatoes. 
tures are wheat, corn (IV ${ }^{\text {th }}$ class), and the less favourable are potato and flax for iol ( $\mathrm{VI}^{\text {th }}$ class). The qualitative potential of the soils of Banat is dwindling from the west to east and from the north to the south.

4. After the researches referring to the quality of agricultural lands, it can be noticed that a part of the piedmountain lands are not efficiently used for ploughing lands. In the same way, it can be said that the fruit plantations from the law lands of Banat are not always founding the best conditions of developing and fruit growing process.

\section{References}

Ianoş Gh., Goian M., 1995, Solurile Banatului - geneză şi caracteristici agrochimice, Ed. Mirton, Timişoara, 292 pp.

Ianoş Gh., Puşcă I., Goian M., 1997, Solurile Banatului - condiții naturale şi fertilitate, Ed. Mirton, Timişoara, 392 pp.

Teaci D., 1980, Bonitarea terenurilor agricole, Ed. Ceres, Bucureşti, 265 pp.

x x x, 1987, Metodologie elaborării studiilor pedologice, vol. I, II, III, ASAS-ICPA, Bucureşti
Table 2 The classes of favorability of the arable lands for the main culture plants in Banat (according to the agricultural surface-1,198,264 hectares)

\begin{tabular}{|c|c|c|c|c|c|c|}
\hline \multirow{2}{*}{$\begin{array}{l}\text { The class of favor. } \\
\text { points }\end{array}$} & \multirow[t]{2}{*}{ UM } & \multicolumn{5}{|c|}{ Usage (ha / \%) } \\
\hline & & Wheat & Corn & Sun flower & Sugar beat & Clover \\
\hline \multirow{2}{*}{$\begin{array}{c}\mathrm{I} \\
91-100\end{array}$} & $\mathrm{Ha}$ & 21,705 & 102,885 & 25,146 & 70,658 & - \\
\hline & $\%$ & 1.82 & 8.59 & 2.10 & 5.90 & \\
\hline \multirow{2}{*}{$\begin{array}{c}\text { II } \\
81-90\end{array}$} & $\mathrm{Ha}$ & 190,682 & 152,203 & 196,163 & 144,070 & \\
\hline & $\%$ & 15.92 & 12.71 & 16.38 & 12.03 & \\
\hline \multirow{2}{*}{$\begin{array}{c}\text { III } \\
71-80\end{array}$} & $\mathrm{Ha}$ & 106,706 & 43,086 & 87,850 & 82,601 & 189,136 \\
\hline & $\%$ & 8.91 & 3.60 & 7.34 & 6.90 & 15.79 \\
\hline \multirow{2}{*}{$\begin{array}{l}\text { IV } \\
61-70\end{array}$} & $\mathrm{Ha}$ & 56,205 & 100,016 & 50,141 & 54,479 & 103,019 \\
\hline & $\%$ & 4.70 & 8.35 & 4.19 & 4.55 & 8.60 \\
\hline \multirow{2}{*}{$\begin{array}{c}\mathrm{V} \\
51-60\end{array}$} & $\mathrm{Ha}$ & 180,703 & 92,141 & 90,441 & 96,571 & 184,747 \\
\hline & $\%$ & 15.09 & 7.69 & 7.55 & 8.06 & 15.42 \\
\hline \multirow{2}{*}{$\begin{array}{c}\mathrm{VI} \\
41-50\end{array}$} & $\mathrm{Ha}$ & 145,087 & 127,792 & 130,154 & 127,490 & 208,170 \\
\hline & $\%$ & 12.11 & 10.67 & 10.87 & 10.64 & 17.38 \\
\hline \multirow{2}{*}{$\begin{array}{c}\text { VII } \\
31-40\end{array}$} & $\mathrm{Ha}$ & 149,117 & 130,226 & 173,099 & 120,330 & 163,165 \\
\hline & $\%$ & 12.45 & 10.87 & 14.45 & 10,05 & 13.62 \\
\hline \multirow{2}{*}{$\begin{array}{l}\text { VIII } \\
21-30\end{array}$} & $\mathrm{Ha}$ & 114,249 & 148,328 & 115,181 & 133,675 & 147,694 \\
\hline & $\%$ & 9.54 & 12.38 & 9.62 & 11.16 & 12.33 \\
\hline \multirow{2}{*}{$\begin{array}{c}\mathrm{IX} \\
11-20\end{array}$} & $\mathrm{Ha}$ & 69,585 & 68,435 & 100,552 & 99,966 & 70,172 \\
\hline & $\%$ & 5.81 & 5.72 & 8.40 & 8.35 & 5.86 \\
\hline \multirow{2}{*}{$\begin{array}{c}\mathrm{X} \\
1-10\end{array}$} & $\mathrm{Ha}$ & 164,225 & 233,152 & 229,537 & 268,424 & 132,161 \\
\hline & $\%$ & 13.71 & 19.46 & 19.16 & 22.40 & 11.03 \\
\hline
\end{tabular}

